\title{
Towards Evidence Based Policy Making in GIAHS: Convention Theory and Effects of GIAHS Registration on the Wholesale and Retail Trade of Traditional and Local Vegetables
}

\author{
Yoshitaka Miyake ${ }^{1}\left(\mathbb{D}\right.$, Yuta Uchiyama ${ }^{1}\left(\mathbb{D}\right.$, Yoshinori Fujihira ${ }^{2} \mathbb{D}$ and Ryo Kohsaka ${ }^{1, *(\mathbb{D}}$ \\ 1 Graduate School of Environmental Studies, Nagoya University, Nagoya, Aichi 464-8601, Japan; \\ miyake.yoshitaka@k.mbox.nagoya-u.ac.jp (Y.M.); uchiyama.yuta@k.mbox.nagoya-u.ac.jp (Y.U.) \\ 2 Muroran Institute of Technology, Muroran, Hokkaido 050-8585, Japan; yfuji@mmm.muroran-it.ac.jp \\ * Correspondence: kohsaka.ryo@f.mbox.nagoya-u.ac.jp
}

\section{check for} updates

Citation: Miyake, Y.; Uchiyama, Y.; Fujihira, Y.; Kohsaka, R. Towards Evidence Based Policy Making in GIAHS: Convention Theory and Effects of GIAHS Registration on the Wholesale and Retail Trade of Traditional and Local Vegetables. Sustainability 2021, 13, 5330. https://doi.org/10.3390/su13105330

Academic Editor:

Anastasios Michailidis

Received: 7 April 2021

Accepted: 6 May 2021

Published: 11 May 2021

Publisher's Note: MDPI stays neutral with regard to jurisdictional claims in published maps and institutional affiliations.

Copyright: (c) 2021 by the authors. Licensee MDPI, Basel, Switzerland. This article is an open access article distributed under the terms and conditions of the Creative Commons Attribution (CC BY) license (https:// creativecommons.org/licenses/by/ $4.0 /)$.

\begin{abstract}
This study examines how the registration of certain agricultural regions affects the sales of vegetables classified as traditional. We focused on the sales trends of traditional vegetables from the Noto region, one of the first designated sites of Globally Important Agricultural Heritage Systems (GIAHS). We compared the sales of recognized traditional vegetables to those of similar traditional vegetables from nearby areas and vegetables labeled with the same place names as the traditional vegetables but without elements of traditionality in branding. The study analyzed the sale and relevant trends of four categories of vegetable: Kaga vegetables, vegetables labeled "Kaga", Noto vegetables, and vegetables labeled "Noto". We further analyzed the trends by applying Convention Theory to understand the underpinning "orders of worth" in the purchase and sale of the items. Both Noto vegetables and place-labeled vegetables increased in overall sales since GIAHS registration in 2011. The recent increases in sales volume and number of items, however, were largely due to the production of lettuce, a crop from a vegetable factory. By applying Convention Theory, we identified that in the agriculture of the region, industrial farming impacted even the GIAHS registered site. Thus, careful collection and analysis of evidence is necessary to evaluate the effects of GIAHS registration and draft an action plan for further evidence-based policy making.
\end{abstract}

Keywords: GIAHS; traditional vegetables; convention theory; evidence-based policy making; Noto; Japan

\section{Introduction \\ 1.1. GIAHS and Traditional Vegetables}

The Food and Agriculture Organization of the United Nations (FAO) initiated designations of Globally Important Agricultural Heritage Systems (GIAHS) in 2002. The designations are intended to recognize agricultural practices and areas with aesthetic and unique agricultural landscapes characterized by agricultural biodiversity, resilient ecosystems, and rich cultural traditions. Since the first designations, GIAHS sites increased to a total of 45 sites in Eurasia, the Americas and Africa as of 2017 [1,2]. FAO has been engaged in long-term conservation through GIAHS. For this cause, FAO formulated strategies for GIAHS, including capacity building of agricultural communities in the systems as well as governments from local to national levels. In contrast to the UNESCO system for registering World Heritage Sites, GIAHS emphasize practices and their sustainability [3].

There are pre-requisites; GIAHS sites need to be in member countries of the FAO [4]. Governments or other stakeholders develop the proposal, and a relevant government agency or GIAHS National Committee gives the proposal to the FAO's GIAHS Secretariat to qualify to apply for the GIAHS registration. The proposal is required to demonstrate unique agri-environmental characteristics and practice. They include natural and cultural landscape features to sustain food production, livelihood, and biodiversity. The action plan 
needs to mention the difficulties to keep the agri-environmental system of a GIAHS site and policies and actions to tackle difficulties. The GIAHS Secretariat initially reviews the proposal, and the Scientific Advisory Group (SAG) reviews the proposal, conducts a site visit, and decides the designation. Once the applicant gets the designation of a GIAHS site, the FAO publicizes the designation on their GIAHS homepage. Afterward, the national government is involved in the monitoring and evaluation of the progress to implement the action plan of a site. The process requires the applicant to pay for proposal preparation and a site visit.

Under this GIAHS system, farmers are expected to be capable of sustainable agricultural production and service provision to conserve agricultural landscape in a GIAHS site [5]. Simultaneously, related agents expect rural revitalization through these productions and service provisions. Thus, farming communities are expected to contribute to conservation through the sustainable production and sale of agricultural products and through related services. Farmers and local governments have presumed that GIAHS registration would result in certain economic opportunities, such as improved branding of agricultural products or increases in green tourism $[5,6]$.

This study selected the Noto GIAHS area in Ishikawa Prefecture, Japan to evaluate the sales trends of vegetables for the period after GIAHS registration and other events that are transportation related. Examples of transportation-related events include connection to the shinkansen in 2015, directly linking the region with the Tokyo metropolitan area. Ishikawa is located in the central part of Honshu Island on the Sea of Japan coast. The prefectural capital, Kanazawa City, is approximately $294 \mathrm{~km}$ west-northwest of Tokyo. Noto is located in Ishikawa Prefecture; Kaga is a name of a feudal domain, centering Kanazawa City. Ishikawa Prefecture experienced a slight population decrease of $2 \%$ for the period of this research from 2010 to 2019, though Kanazawa City experienced slow population growth (Figure 1) [7]. Alternatively, the population in the Noto region decreased by $13 \%$. The population density of the Ishikawa Prefecture, Kanazawa City, the Kaga region, and the Noto region are respectively 270, 987, 431, and 90 people $/ \mathrm{km}^{2}$ in 2020 [7]. Thus, rurality increased from Kanazawa City, the surrounding Kaga region, to the Noto region. To analyze the sales trend of traditional vegetables from Noto, the vegetables branded or labeled with Kaga are the comparative examples in this study (Table 1). Furthermore, the analysis includes comparison with three other categories of vegetable products: first, with registered traditional vegetables in the neighboring area of Kaga, and also with two nontraditional local categories that are labeled with Noto and Kaga as place names. Thus, this study analyzed sales trends of four categories of vegetables: Noto vegetables, vegetables labeled with Noto as the place name, Kaga vegetables, and vegetables labeled with Kaga as the place name (following the same categories as [8]).

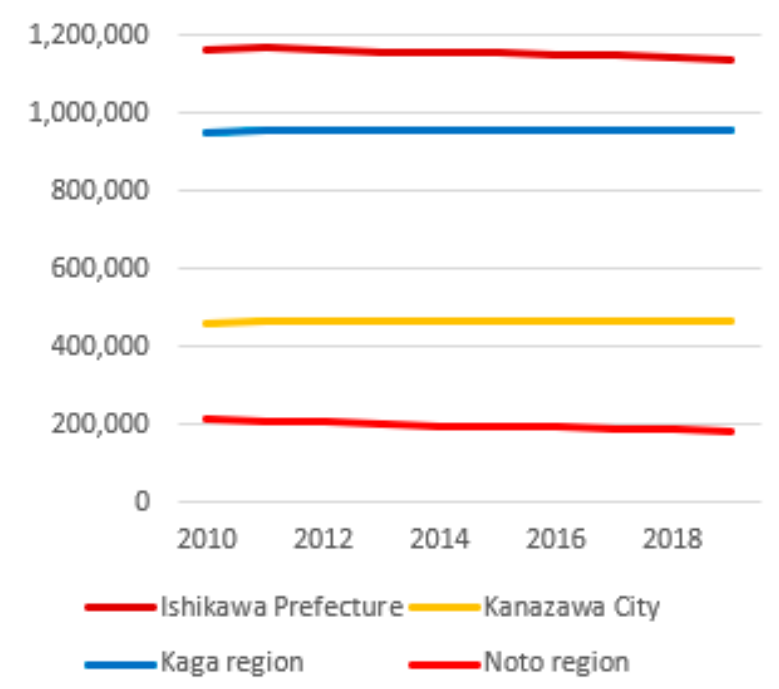

Figure 1. Population changes in Ishikawa Prefecture. Source: [7]. 
Table 1. Traditional vegetables and the vegetables with place names in this study.

\begin{tabular}{cl}
\hline Kaga vegetable & $\begin{array}{l}\text { Traditional vegetables produced in Kanazawa City. } \\
\text { Production history dates back at least to } 1945 .\end{array}$ \\
\hline Products with Kaga as place name & $\begin{array}{l}\text { Are not registered as Kaga vegetables. They have } \\
\text { place names such as Kaga, Kanazawa, Minami Kaga, } \\
\text { and Hakusan (cities, districts, or neighborhoods) as } \\
\text { part of the product name. }\end{array}$ \\
\hline Noto vegetables & $\begin{array}{l}\text { Traditional vegetables and specially produced } \\
\text { vegetables in Noto. Traditional vegetables must have } \\
\text { about 30 years of production history or longer in } \\
\text { Noto. The other vegetables are recognized in } \\
\text { production promotion campaigns of local } \\
\text { governments and agricultural cooperatives in Noto. }\end{array}$ \\
\hline \multirow{2}{*}{ Products with Noto as place name } & $\begin{array}{l}\text { They are not registered as Noto vegetables. They } \\
\text { have place names such as Noto, Okunoto, Shiga, and } \\
\text { Wajima as part of the product names. }\end{array}$ \\
\hline
\end{tabular}

\subsection{Traditional Vegetables in Japan}

In the last three decades, traditional vegetables have attracted the interest of scholars in contemporary Japan [9-13]. Traditional vegetables have also become a measure of agricultural revitalization. Attaching place names to vegetable names can stimulate place-based branding and agricultural revitalization $[8,14]$. The definitions of traditional vegetables are not uniform but locally decided and applied in a diverse way $[8,15,16]$. Certain definitions are relatively strict, such as time-based definitions where historical length of cultivation differs. For example, to be labeled Kyoto vegetables (Kyoyasai), the vegetables should have been cultivated beginning no later than 1868, the year of the Meiji Restoration, which was the symbolic beginning of the modern era. The length of cultivation for Kaga vegetables (Kaga yasai) should be before 1945, the year in which WWII ended, marking the beginning of the contemporary era. To be designated as traditional vegetables in Noto, Noto vegetables or Noto yasai must have been cultivated for about 30 years or longer. In addition to temporal standards, there are spatial standards as well; the designation Kaga yasai can exclusively be used for vegetables cultivated within the geographical boundaries of Kanazawa City. The other neighboring areas, including Kaga City, are not entitled to use the brand name Kaga yasai. The argument in this study is that the designation of Kaga vegetables is stricter than that of Noto vegetables. Noto vegetables include both traditional vegetables and vegetables specially produced for the purpose of the promotion of local agriculture [17]. Kaga vegetables are further institutionalized with the registration of a Regional Collective Trademark.

Conventionally, traditional vegetables tend to be grouped by region and branded with the place name of a production region. They are expected to be a measure of agricultural revitalization and location marketing in Japan. As the lack of a uniform definition demonstrates, the economic influence of such efforts may well be different by region. Alternatively, such ambiguity in temporal and spatial qualities and modes of production are not only negative but can be strategic and can enable different stakeholders to engage in the same branding [16].

With a similar framework, Uchiyama et al. [8] analyzed the datasets of the same stores from 2010 to 2015 as this study. According to the study by Uchiyama et al., the number of items sold as traditional vegetables slowly increased over time. The addition of place names to the product names of the non-traditional vegetables contributed to sales. Events such as GIAHS registration and the connection of the region to the shinkansen may also have increased the sales of the four kinds of vegetables. Consumers purchasing traditional vegetables, Kaga vegetables, were also analyzed according to the types of media or sources from which they obtain local information. It was determined that mass media, such as TV and newspapers, and "accessible" media, such as direct conversations in shops, increased 
the purchases of the vegetables [18]. Within four years after the study by Uchiyama et al. [8], the trend of some vegetable categories had changed; for example, wholesalers stopped handling Noto vegetables. This study analyzes the changes in the sales of the vegetables and their causes.

\subsection{Applying Convention Theory}

This study applied Convention Theory to analyze the shifts of the sales of traditional and local vegetables in the GIAHS site and a neighboring area. The theory focuses on social construction of product qualities $[19,20]$. Regarding the values and corresponding articulations, Boltanski and Thévenot [21] suggest "orders of worth," or so-called "cities." The orders are primarily industrial, market, reputation and opinion, domestic, and creativity and inspiration (Figure 2). An industrial order is related to mass production and scientific management. A market order is related to prices and market competition. An order of reputation and opinion is related to recognition and popularity. A domestic order is related to production and branding at scales ranging from local to national, and to historical narratives supporting the value. Creativity and passion are related to breakthrough and the passion to advance into unknown territory. A domestic order of worth, a value related to the appreciation of local and domestic production, could apply to the qualities of traditional and local vegetables and their sales [22,23]. Applying orders of worth, this study researched Noto vegetables and the vegetables labeled with Noto as a place name to analyze the current quality and sales of traditional and local vegetables from a GIAHS site with rich ecological and cultural traditions.

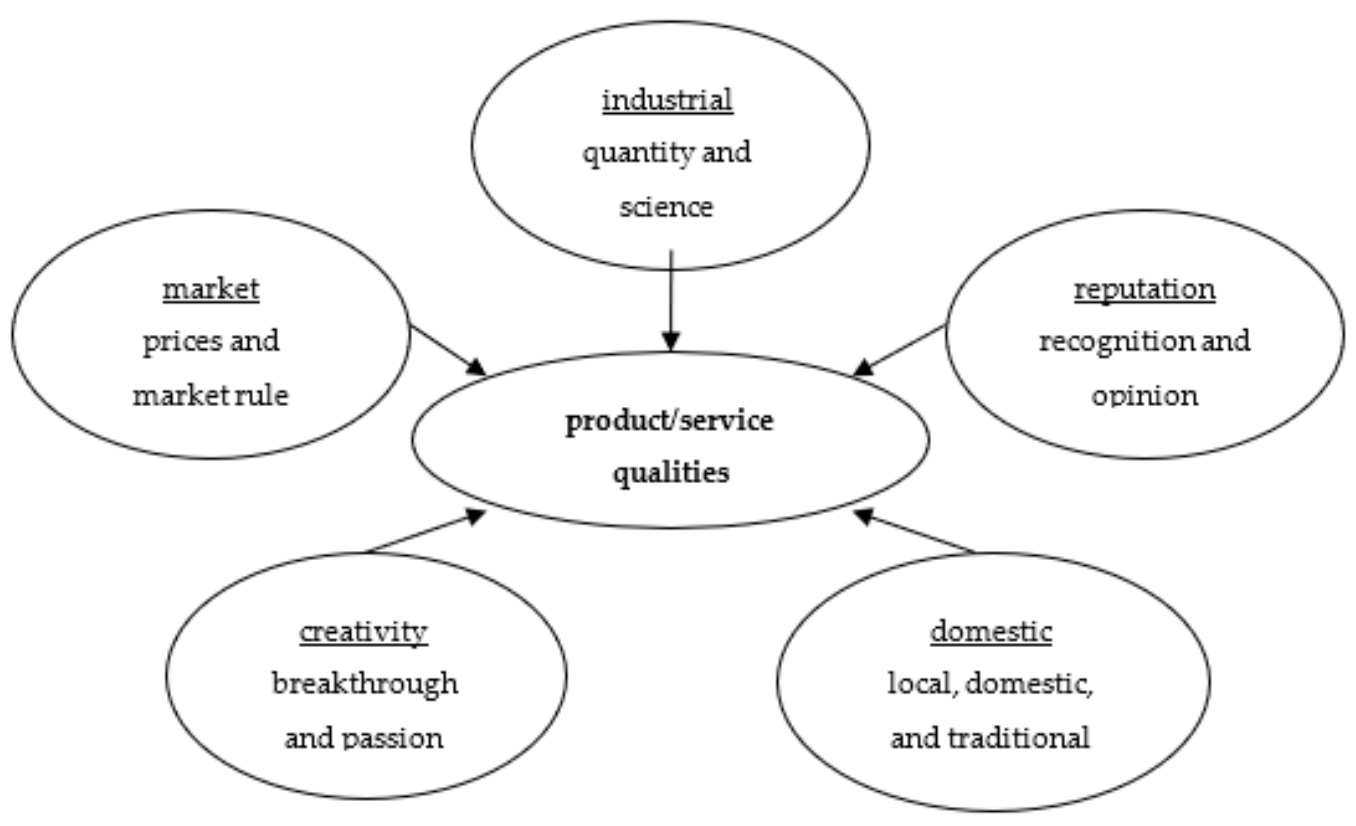

Figure 2. Qualities and values in Convention Theory.

\subsection{Purpose of Study}

This study examines the trend of the sales and price of traditional vegetables in a GIAHS site to examine the pros and cons of the ambiguity of products resulting from branding products as traditional vegetables or local vegetables. As the following step, we applied Convention Theory to interpret the trend. Specifically, the following four categories of vegetables were compared: Kaga vegetables, the vegetables labeled with Kaga as the place name, Noto vegetables, and the vegetables labeled with Noto as the place name. These data were taken from a co-op catalogue titled "Jiwa-mall" that showcases local and traditional foods. Besides these quantitative data, we conducted interviews of retailers, wholesalers, and prefectural government staff. Interviews aimed to clarify agricultural, social, and geographic influences of GIHAS registrations on agricultural products. For 
the four categories, we compared the following: (1) the number of the traded item types; (2) the average prices of the items; (3) sales revenue; and (4) the number of customers who purchased each item.

\section{Methods}

This study analyzes the sales trends of traditional and local vegetables through sales data from a regional consumer co-op in Ishikawa Prefecture. The co-op started in 1976, and it had 133,339 members in 2015 [8]. In general, the members have higher awareness of and motivations for paying attention to food safety and environmental issues. The members can order products from catalogs and receive the products by delivery usually on the following day when ordering over the internet or in two weeks if using paper order forms. It normally requires a week or longer from order placement to delivery. The co-op publishes catalogues weekly for members; the catalogues range from ordinary products to specialty local and regional products, including traditional and local vegetables, that are showcased in a separate catalogue.

Consumer cooperatives have been an important part of Japanese society since they were first formed in the year 1900. They have emphasized cooperative purchase of environmentally friendly and healthy products and kept loyal member families [24]. Member households can either shop at co-op stores or receive the products through the delivery to a group. The majority of co-ops currently accept delivery to individual households to accommodate couples working out of their house. Customers who take home delivery place orders from catalogs of products offered by the co-op.

From the various catalogs, this study focuses on a catalogue titled "Jiwa-mall" that showcases local and traditional foods. Jiwa-mall is named after jiwamon, a dialect term from Kanazawa meaning "hometown dishes and foods." Jiwa-mall is thus intended for locals with specific preferences for domestic origins or tastes, and items consist exclusively of products from Ishikawa and the neighboring prefectures of Fukui and Toyama. The prices of the products in Jiwa-mall tend to be fixed, with few fluctuations. Prices are determined based on market conditions three months prior to the publication of the catalogues. It takes a month to receive the orders after the publication of the catalogues. A typical customer profile is a female or housewife in her forties or fifties.

In this study, products are analyzed in four categories: Kaga vegetables (registered with collective trademarks), the vegetables labeled with Kaga as the place name, Noto vegetables (recognized by the prefecture), and the vegetables labeled with Noto as the place name (Table 1$)$.

Kaga vegetables comprise 15 kinds of traditional vegetables branded by a trade association supported by Kanazawa City, the capital of Ishikawa Prefecture [25]. The efforts to brand the vegetables have a history of over three decades. Kaga vegetables are registered as a Regional Collective Trademark. Consequently, there is a spatial boundary as well; the brand "Kaga vegetables" can only be used within the geographical boundary of Kanazawa City, as mentioned earlier. The name Kaga is especially resonant because it is not only the name of a contemporary city, but it was also the name of the medieval domain centered in Kanazawa. By definition, Kaga vegetables have been produced since the time before 1945, the year when WWII ended. Kanazawa City Agricultural Produce Branding Association, supported by the city, is in charge of the registration and promotion of the vegetables. The association provides the definition of the production area for each kind of Kaga vegetables and a logo to attach on the vegetables for sale. There have been major changes in regional transportation systems as well. In 2015, the Hokuriku Shinkansen began service to the region, and Kanazawa Station is currently the terminal station of this line from Tokyo Station via Saitama, Nagano and Toyama Prefectures.

Noto vegetables comprise 17 kinds of vegetables produced in the cultural and natural landscapes of the Noto region. The Noto region is a peninsula to the north of Kanazawa encompassing four cities and seven towns [17]. In 2011, FAO registered the region as one of the first GIAHS sites in Japan (the other was Sado City, encompassing the entirety of Sado 
Island, which forms part of Niigata Prefecture to the northeast of Ishikawa). As symbolized in the traditional cultural landscape term, "Satoyama" used for the FAO registration; it is a typical rural landscape. The "Noto vegetables" brand includes both traditional and locally produced vegetables in the region. The production history of traditional vegetables in Noto is about 30 years or longer, shorter than the period for Kaga vegetable brands. The locally produced vegetables are representative vegetables with comparative advantages when compared with vegetables from other regions. The prefectural government and local agricultural cooperatives highlighted special characteristics of local varieties to increase production and sales. An office in the Ishikawa Prefectural Government oversees promotion and branding [8]. The office decides the definition of the production area and a logo to attach on the vegetables, similar to the way for Kaga vegetables.

Unlike these registered or marketed products with specific scopes, the categories of place names that include Kaga or Noto are more general categories, simply indicating to buyers the place of production. One example is the label or designation "Carrots from Noto region" which does not give further indications for history or quality. Such designations certainly have the connotations of "tradition" for Kaga or "nature" for Noto but are vague and implied compared to the vegetables sold under registered brands. Jiwa-mall catalogs describe producer names and production areas. Wholesalers propose the vegetables to sell with place names and the names of producers. In addition to the vegetable types, production areas and producer names are possibly printed in the catalogs. The catalogs at least indicate producing prefectures since they include the vegetables only from the three prefectures, including Ishikawa. The co-op recommends the proposal with the vegetables with more specific production areas and producer names, and these sell with higher prices in Jiwa-mall [Personal conversation with co-op staff, 11 March 2021].

Each vegetable type was not necessarily unique to an individual vegetable category in this study. Kaga vegetables were an exception in this regard, only including the vegetable types classified to this category. Noto vegetables included both traditional and nontraditional vegetables. Vegetables with Noto and Kaga as place names did not indicate vegetable types identified as the products solely from each region. Thus, certain types of vegetables were found in multiple vegetable categories of this study. Pumpkins were found in three categories; bracken, carrots, cherry tomatoes, Chinese cabbages, potatoes, spinach, and sweet potatoes were found in two categories.

Based on the four vegetable categories, this study examined sales, prices, and customers by analyzing the trends of purchases made by co-op members. The co-op electrically provided their in-house data for the period from 2010 to 2019. The analysis was conducted for Jiwa-mall catalogs by aggregating and analyzing (1) sales; (2) the number of customers buying each item; (3) annual sales figures; (4) the number of listed items; and (5) average prices across the four categories of the vegetables. Prices in this study were nominal. The study could investigate the comparison of the four vegetable categories whether the prices were real or nominal. This study first applied descriptive statistics to compare the temporal trends among the four vegetable categories in these five data types (Figures 3-7).

This study further analyzed the effects of the GIAHS registration in 2011 on price, sales, and consumers by simple regression analysis $(p<0.05)$. The analysis respectively assigned 0 and 1 to the time period until a particular year and the period after the year: this independent variable was based on the years 2011 and 2012. The analysis was applied to Noto Pumpkin, Noto Watermelon, and Nakajimana, a type of leaf vegetable, because the data of them contained the data until and after the years of interest and the product names, including amount or weight. The analysis included the unit price, sales in number or weight, sales per person, and purchased numbers or weight per person as dependable variables in addition to price, sales by monetary value, and consumers.

To complement the data analysis, we conducted phone interviews with staff of the co-op and representatives of wholesalers of fresh produce in the region in May 2020 (once for each interviewee: one staff member from a co-op and two wholesale dealers). They were asked about the reasons for certain unexpected trends found through the analysis of the 
recent data. These were followed by an email communication with co-op staff in March 2021 to ask about the way to identify the locations of vegetable productions. Uchiyama et al. [8] conducted a similar study, but we added four recent years to the analysis. This identified the distinctive trend reflecting the social change of the Noto GIAHS. Wholesalers and retailers of this study stopped handling Noto vegetables. The identified trends provided a better understanding about the effectiveness of the drivers of ongoing sales changes of traditional and place-labeled vegetables. Furthermore, simple regression extricated certain factors on the declining trade of Noto vegetables.

\section{Results}

Our results suggest that the seeming increase in sales of "local" or "traditional" foods, at first glance, provides a different picture when analyzed in detail, applying Convention Theory. The comparison with different vegetable categories in the same GIAHS area and traditional and non-traditional vegetables from a different area can further clarify the prospect of producing traditional vegetables for the conservation of GIAHS communities and landscape.

\subsection{Sales, Customers, and Sales Figures of Branded and Place-Labeled Vegetables}

We analyze four vegetable categories from the perspectives of overall trend: sales, customers, listed items, and prices. In this section, we focus on trends in the sales and number of purchasing customers by items in the individual category. The annual sales of the vegetables under the four categories are shown in Figure 3. Comparing Figures 4 and 5, the fluctuations of the customers and sales figures show a similar trend across the categories throughout the analysis period. Thus, we focus on customer trends by examining the numbers of customers in temporal sequence for individual categories as shown in Figure 4. The general trends in sales increased in 2011 and 2015. These increases are partially due to GIAHS registration in 2011 and the shinkansen connection in 2015. The effect of the population change on the trade of the four vegetables was rather small since the trend of the population change was stable (Figure 1).

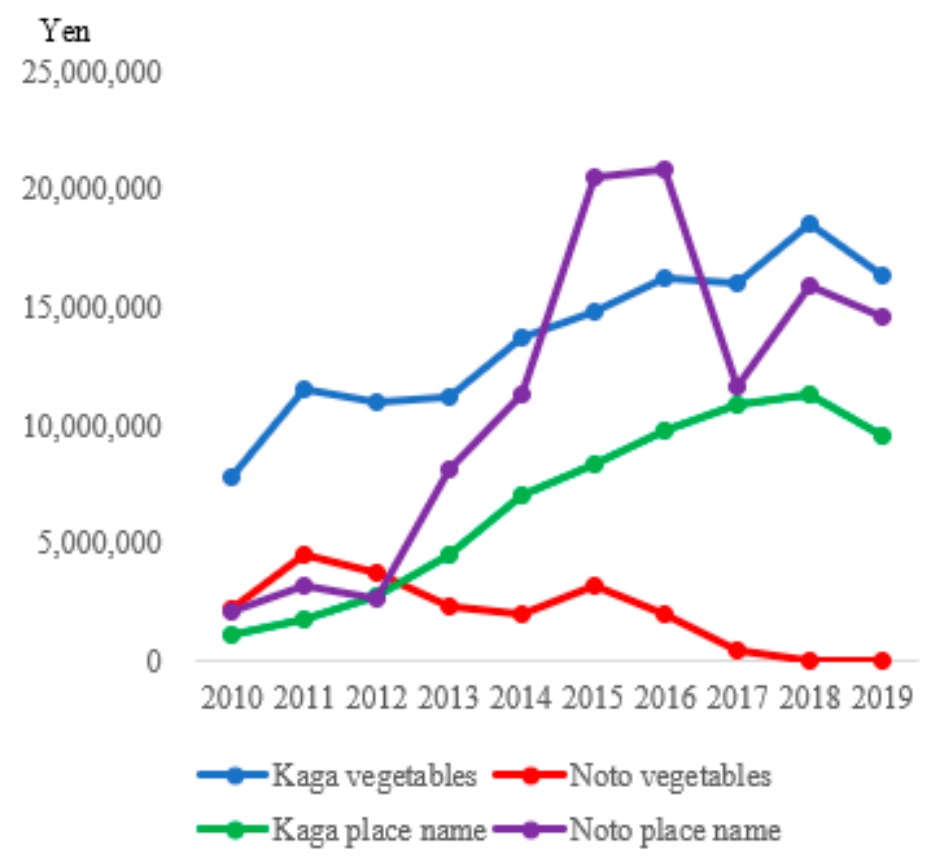

Figure 3. Sales of vegetables in four categories. 


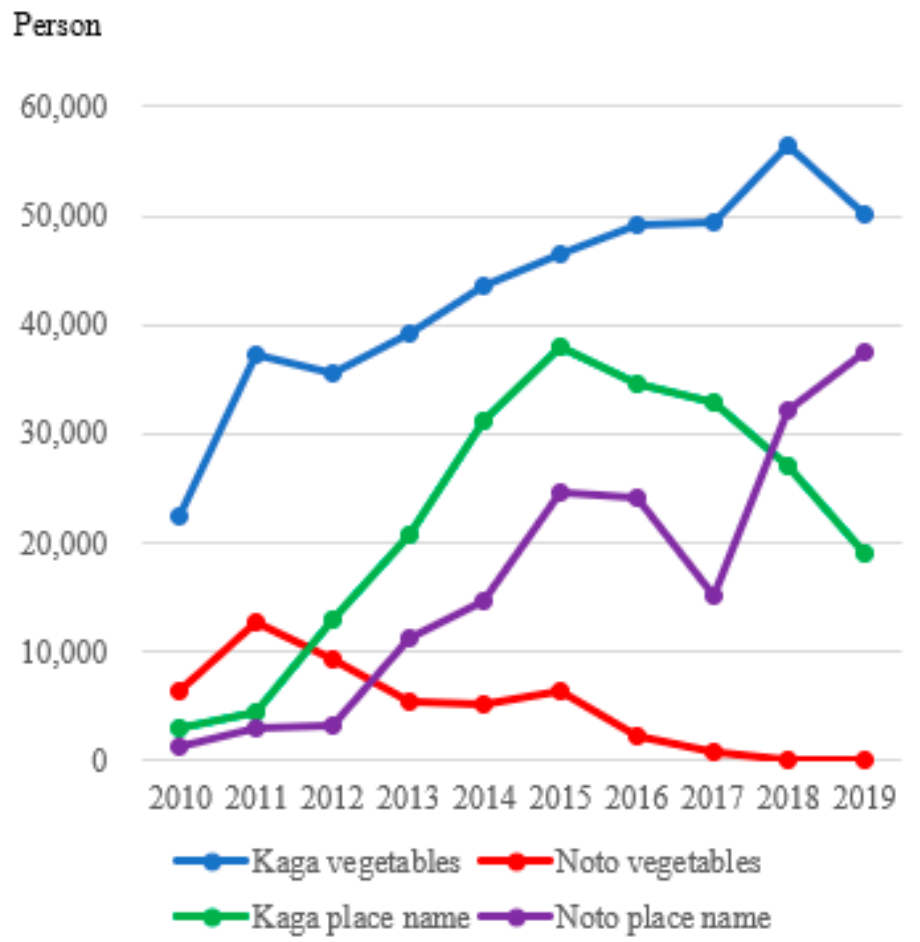

Figure 4. Purchasing customers in four categories. Note: This figure is a cumulative total; for example, a single customer buying two kinds of item in a single purchase is counted as two customers.

\section{Number in sales figure}

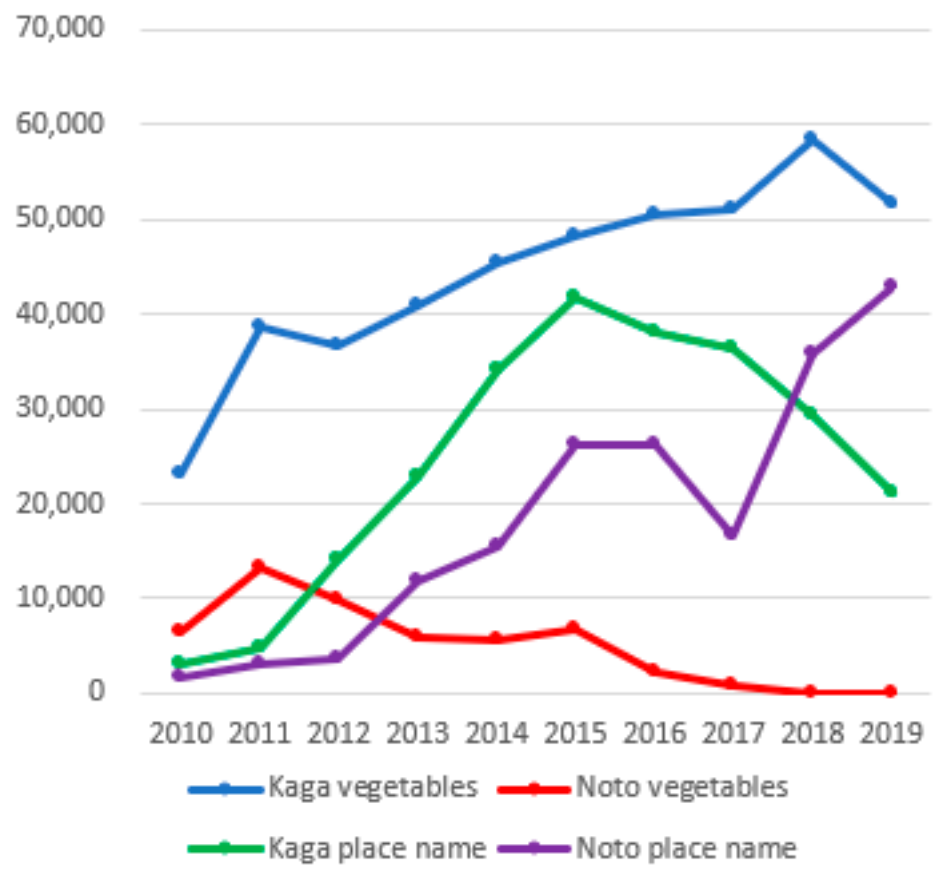

Figure 5. Annual sales figure in four categories.

Specifically, for the category of Kaga vegetables, both the sales and number of purchasing customers increased during the period analyzed. Sales increased from JPY 7.7 million in 2010 to JPY 16.3 million in 2019 (Figure 3). The number of purchasing customers increased from 22,358 to 50,204 (Figure 4).

As for the vegetables with Kaga as the place name, the picture is more mixed, showing partial increases but also decreases in recent periods. The sales steadily increased from JPY 
1.1 million in 2010 to JPY 11.3 million in 2018 (Figure 3) but bottomed out at JPY 9.5 million in 2019. The number of customers increased from 1391 in 2010 to 37,873 in 2015; however, it decreased to 34,701 in 2016 and 19,027 in 2019 (Figure 4). Thus, when both sales and customer numbers increased from 2010 to 2015, the increase in customers underpinned the increase in sales. Subsequently, higher unit prices of the items may have underpinned the increase in total sales revenue in the latter period, until 2018.

As for Noto vegetables, sales increased in 2011 and 2015 (Figure 3). The sales decreased until Jiwa-mall (the catalogue specialized for local and traditional foods) stopped selling Noto vegetables in 2018. The fluctuations in sales were similar to those of customers (Figures 3 and 4). The increase in 2015 could partially be attributed to the spill-over effects of the shinkansen connection to Kanazawa on the overall region. Then, Jiwa-mall stopped selling Noto vegetables from 2018. When asked during the interview the reasons for the halt in sales, a wholesaler explained that it was because the overall amount and stability of the supply of Noto vegetables was not sufficient to sell to supermarkets and co-ops [personal conversation, 14 May 2020]. The small amount was partially attributed to the small size of the average farm and the aging of the farming population.

As for the product category with Noto as the place name, overall sales revenue generally increased from JPY 2.1 million in 2010 to JPY 14.5 million in 2019 (Figure 3). However, sales have fluctuated during recent years. After the steep decrease from JPY 20.8 million in 2016 to JPY 11.6 million in 2017, sales recovered to JPY 15.9 million in 2018 but decreased to JPY 14.5 million in 2019. Similarly, the number of customers steadily increased from 1391 in 2010 to 24,677 in 2015 (Figure 4). The number of customers decreased to 15,223 in 2017 but dramatically increased to 37,614 in 2019 . The main vegetable types with Noto as the place name have been changing, and customers reacted to these changes by purchasing the newly introduced products. Table 2 shows items with annual sales of more than JPY 1 million, and their shares of the total in 2011, 2016, and 2018, the peak years of the fluctuations. Frozen blueberries were the principal item in 2011 and 2016 (with sales of JPY 2.5 million (76.4\% of total sales for all items in the product category with Noto as the place name during the year) and JPY 3.1 million (33.2\%), respectively). Korokaki, dried persimmons, registered for geographical indication, emerged second in 2016 and third in 2018 (JPY 2.2 million (23.4\%) and JPY 1.5 million (16.4\%), respectively). The main crops became diversified, as both spinach and Chinese cabbages reached over JPY 1 million in sales (JPY 1.4 million (15.3\%) for spinach and JPY 1.1 million (12.1\%) for Chinese cabbages in 2016). In addition to the sales increases of frozen blueberries and Korokaki, the diversification underpinned the sales revenue increase from 2011 to 2016. Lettuce became the principal item in 2018 (JPY 4.3 million (46.0\%)), though the sales of both frozen blueberries and Korokaki decreased compared with those in 2016 (JPY 2.2 million (24.1\%) for frozen blueberries and JPY 1.5 million (16.4\%) for Korokaki in 2018).

Table 2. Vegetables with Noto as the place name with sales of more than JPY 1 million per year and their shares of total sales in peak years of fluctuations (2011, 2016, and 2018).

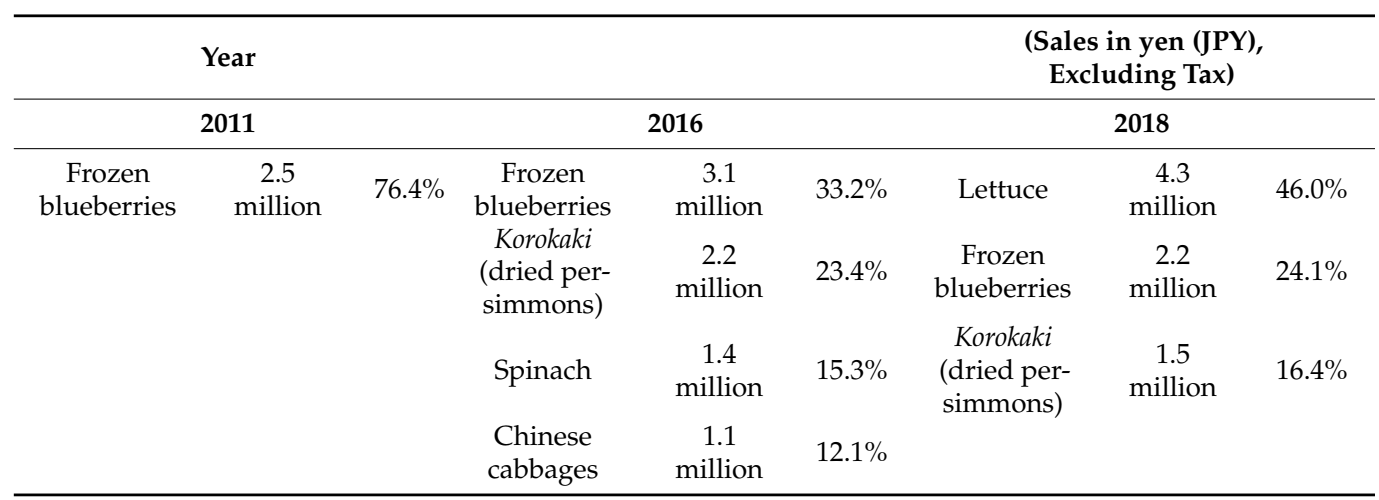


There are no clear trends, and the situation has drastically changed since the onset of the COVID-19 crisis in 2020, the analysis of the effects of which is out of scope for this paper. The listed items and the customers increased in 2018 and 2019. As described earlier, the increase is largely due to the various brands of lettuce produced in the vegetable factories since 2017 ([26], Personal conversation with a wholesaler, 14 May 2020). However, the increases in sellable item types were not accompanied by an increase in sales (Figure 3; Table 2).

\subsection{Number of Branded and Place-Named Vegetables}

The data on the numbers of branded and place-named vegetable items listed in the Jiwa-mall from 2010 to 2019 are illustrated in Figure 6. In general trends for listed items, the increase in item numbers of Kaga vegetables is moderate (64 items in 2010 and 82 items in 2019). In the earlier phase, there was a moderate increase that continued to 2014 (93 items). From 2016 onwards, the numbers stabilized at about 80.

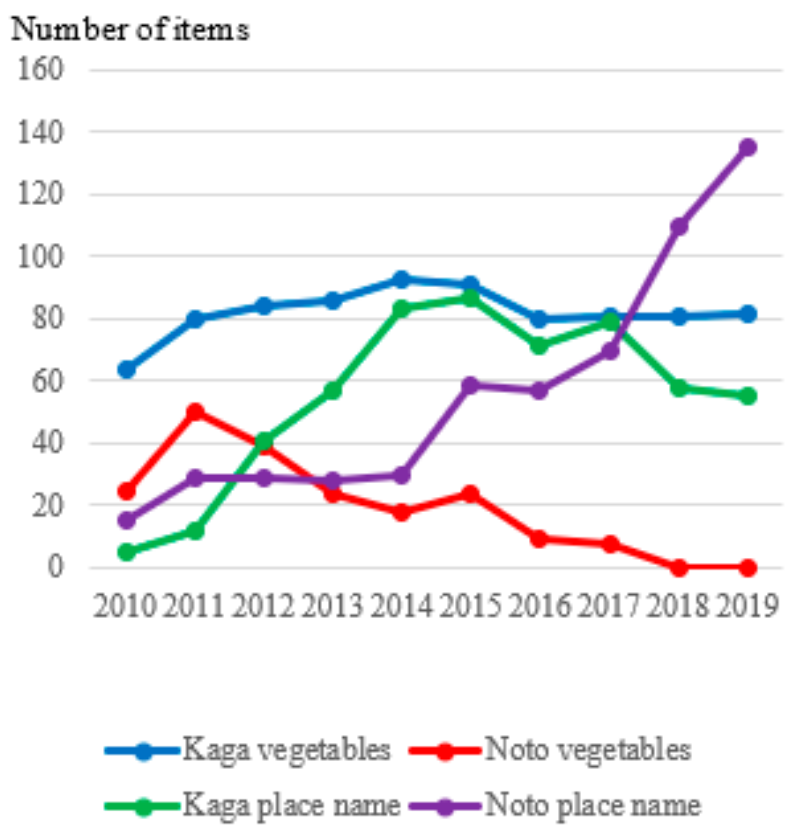

Figure 6. Listed items in the Jiwa-mall catalog across four categories Note: This figure is the total cumulative number of items in the four categories in Jiwa-mall.

Vegetable items with Kaga as the place name increased dramatically, from 5 in 2010 to 55 in 2019. In the earlier phase, the number of items surged to 87 by 2015 . In the following period, the number fluctuated between 55 and 79, and landed at 55 items in 2019. The fluctuation exhibits a downward trend during recent years. As general trends of listed items for both Kaga categories (those branded and with place name), the trends show an increase until 2014 or 2015.

In the earlier analysis, the increase is attributed to the shinkansen connection to Kanazawa in 2015 [8]. A possible explanation is that the increase of tourist interest in Kanazawa also stirred the interest of residents in products with names connected to the local history in the region (which used to be called Kaga).

As for Noto vegetables, the listed items in Jiwa-mall decreased from 25 in 2010 to zero in 2018 and 2019, disappearing from the specialized catalogue. It first increased to 50 items in 2011. There was a general decline in the listing for the brand, except for the year 2015 when the region was connected to the shinkansen system. In general, the handling of Noto vegetables faced difficulties with limited amounts and stability from the supply side, alongside limited recognition among consumers on the demand side. The former is limited by the fact that producers who had conventionally produced Noto vegetables are aging and have small-scale operations. 
As for the category of products with Noto as the place name, the trends of listed items showed a contrasting increase in numbers from 15 in 2010 to 135 in 2019. The increase accelerated in the mid2010s, from 30 in 2014 to 59 in 2015 and 70 in 2017 to 135 in 2019. As shown in Table 2, the recent surge can partially be explained by the introduction of a single item, lettuce, produced in a factory-like built environment. The number of listed lettuce items reached 84 out of 135 total vegetable items with the place name of Noto. The so-called "plant factory" or lettuce production in the Noto region started to operate in 2017 [26]. Their popularity increased rapidly, as there is no need to wash or sanitize the lettuce produced in these facilities. Moreover, these facilities, because they are controlled environments, lead to reductions in labor costs and also total costs. These facilities are also the sole producers of such modern types of lettuce in the prefecture [Personal conversation with a wholesaler, 14 May 2020]. Their supply is stable for wholesalers. The same interviewee added that the place name of Noto potentially supported the spread of the products, as the name of the region evokes nature and gentleness in their connotations among consumers through imagining a symbiotic "Satoyama" landscape with traditional vegetable production and scenic rice terraces. It is, in a sense, ironic that the surge in products in a GIAHS site with a traditional regional name is mainly driven by lettuce produced in a modern factory. When analyzing the trends and the quantity of the lettuce, we need to be aware of such changes in the contents of the items, which may not be the expected types of traditional local foods.

\subsection{Prices of Branded and Place-Tagged Vegetables}

We review the trends of the average prices of the four vegetable categories in Figure 7. The price trends are different among the four categories, though most vegetable types increased in 2015 and 2016. The shinkansen was connected to the region in 2015. Though vegetables with Kaga as the place name decreased in average price from 2014 to 2015, they increased in 2016 (JPY 191.4 in 2014, JPY 186.8 in 2015, and JPY 237 in 2016). The average price of Kaga vegetables is comparatively stable compared with the other three categories. The average price was the highest at JPY 319.2 in 2010 and the lowest at JPY 262.1 in 2013. It increased from JPY 281.0 in 2014 to JPY 297.6 in 2016. In contrast, vegetables categorized with Kaga as the place name decreased in price per item from JPY 352.6 in 2011 to JPY 186.6 in 2012. There was a second price rise that started in 2013, landing at JPY 237.9 from 2013 to 2019. During the same period, the number of listed items in the category decreased (Figure 6). The higher prices of vegetables under the category of Kaga as the place name can be partially attributed to products such as pumpkins and pears, which are sometimes boxed and sold as high-end gifts.

There were also relatively pronounced positive trends for the prices of Noto vegetables from JPY 316.9 to JPY 818.2 on average from 2010 to 2016. The sharp increase, about 70\%, occurred between 2015 and 2016. This could be because some highly priced items, such as watermelons, remained despite the decreasing items listed in Jiwa-mall. The vegetable types with the different package sizes decreased from 2015 to 2016 (9 and 3, respectively). The average prices of watermelons (JPY 1100 in 2015 and JPY 1130 in 2016) were higher than those of Noto vegetables (JPY 442.3 in 2015 and JPY 818.2 in 2016). As the last category, the trends of the vegetables with Noto as the place name has been negative in trend for most of the periods. The average price decreased from JPY 1327.2 to JPY 315.5 in the decade from 2010 to 2019. An exceptionally moderate increase from JPY 678.8 to JPY 739.4 occurred during the period between 2014 and 2016. Despite the increase in the number of items during the period, the demand decreased sooner and the plant factory became a major vegetable supplier in Noto. 


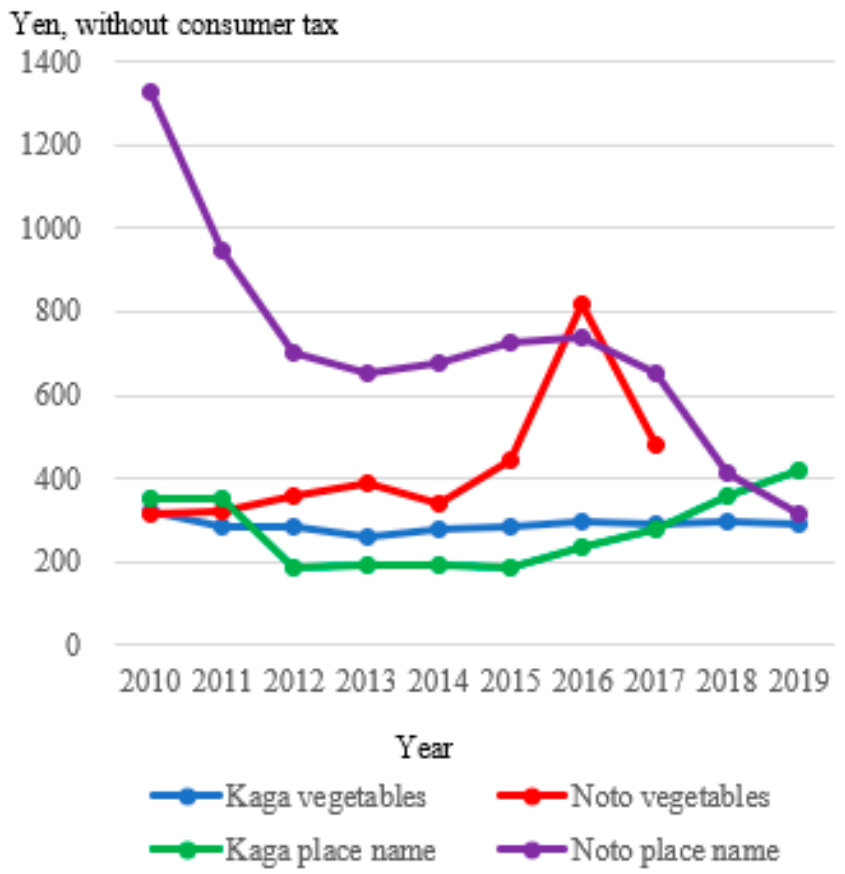

Figure 7. Average prices of vegetables in four categories.

\subsection{The Change around the GIAHS Registration in Noto Vegetables}

Using regression analysis, we surveyed the differences through the years 2011 and 2012 in Noto vegetables. Nakajimana decreased the purchasing weight per person through 2012. Noto Pumpkin significantly increased the price while decreasing the sale per person through 2012. The price increase was not certain with the GIAHS registration, as the analysis did find the significance through 2011. Noto watermelons significantly lowered the price and decreased the sale per person through 2012. The results corresponded to the general trend of decrease in Noto vegetables. Consumers decreased the weight to buy Nakajimana, as consumers were likely to change the number of packages when comparing a watermelon and a pumpkin.

\section{Discussion}

\subsection{General Sales Trend of Traditional and Local Vegetables from a GIAHS Site}

Both the aging of the farmers and their small inefficient farming operations are cited as causes of abandoned farmland. Both Noto vegetables and place-tagged vegetables increased in overall sales after the GIAHS registration in 2011 and the connection to the shinkansen in 2015, respectively. The increases in volume and items, however, were largely due to lettuce products produced in state-of-the-art plant factories. Symbolically, Noto traditional vegetables, the category with traditionality, disappeared from the catalogs in 2018. Furthermore, the average price per item from Noto, for both traditional and place-tagged items, decreased steadily despite an increase in trading volumes. Thus, careful analysis is necessary to determine the effects of GIAHS registrations; the increases in sales and volumes may well be caused by mass-produced commodities instead of traditional or local agricultural products involved in the GIAHS systems. Furthermore, the unstable and short supply of Noto vegetables affected their disappearance from Jiwa-mall in 2018. Though this could apply to the watermelons, they became less favorable to sell in supermarkets in Ishikawa Prefecture. Consumers start to eat watermelons from Kumamoto Prefecture, in southwestern Japan, in May. By the time watermelons from Noto become available, customers tend to be uninterested in eating them [Personal conversation with a wholesaler, 14 May 2020]. Such merchandise related issues underpinned the changes of place labels of watermelons from Noto to the more general Ishikawa. With the produce being sold through the wider market, consumer preference does not necessarily correspond 
to the local seasonality. Such contextualized strategies are required to increase value-added effects for the traditional categories.

The previous section discussed the listed items, prices, and sales of the four categories of the vegetables: two are traditional vegetables and the others are the vegetables with the place names for the period from 2011 to 2019. In addition to the findings of Uchiyama et al. [8], which analyzed trends until 2015, we further identified the disappearance of Noto traditional vegetables from Jiwa-mall and the challenges that producers face. The positive effects of the connection to the shinkansen in 2015 could neither sustain the sales growth of Noto vegetables a year later nor reverse the declining trend. The vegetables with Noto as the place name increased the volumes and sales with lowered prices per items, mainly by the introduction of lettuce production in factories located in the Noto region. In short, the GIAHS registration did not contribute to the increase in vegetable sales for the traditional categories. It is implied that the registration per se might not be able to counter the aging of and decrease in the population of farmers producing traditional vegetables.

\subsection{Cloudy Conventions on Noto Vegetables}

In comparison, the situations and sale dynamics of the traditional vegetables for Kaga vegetables, in the same prefecture, offered a contrast. For Kaga vegetables, the average price was relatively stable, and the vegetable type increased in both sales and customers. In contrast, the sale of Noto vegetables in Jiwa-mall was halted in 2018. By applying Convention Theory analysis, Kaga's success can be attributed to its designation focused on the quality of tradition related to a domestic order established over three decades, not to the GIAHS registration in 2011 (Figure 8). Noto vegetables do not have the same level of the focus. Conventions here are the norms and institutions for the designations and brandings of traditional vegetables. Conventions are rather cloudy in that the standards by the prefectural government for Noto vegetables are less strict than those for Kaga. It could not contribute to the promotion of traditional vegetables in Noto. Furthermore, according to the theory about conventions on production types by Storper and Salais [27], the product differentiation can affect the production and sales as the producers solidify the product quality. This applies to traditional vegetables. The designation of Kaga vegetables demands the production method dating back at least to 1945, which is about 30 years or longer, the required time length for Noto vegetables. Noto vegetables even include non-traditional varieties for the promotion of local agriculture. Thus, Kaga vegetables are more "traditional" than Noto vegetables. As a result, farmers can be more experienced and skilled to enhance and maintain the quality of Kaga vegetables, and Kaga vegetables can be relatively familiar to retailers, chefs, and consumers. Though the designation of Noto vegetables seems flexible, it has not provided the quality necessary to produce and sell compared with Kaga vegetables. The quality of Noto vegetables seems cloudy through comparison.

In registering the GIAHS site, farming communities were supposed to sustain the aesthetic and unique agricultural landscape in a conceptual and intentional level following the FAO's intention. This production in the local GIAHS landscape underpins the quality of a domestic order, and the customers support the connection between local nature and agriculture and trust in the products and their qualities in their aims and designs. Such trends become more truthful about producing and selling high-quality local products [20]. Contrasting to this intention, the traditional vegetables disappeared from the catalogue 7 years after the GIAHS registration, while factory-produced ones sold, contrary to the image of the local and traditional revitalization by the registration. The shift in agriculture could represent the introduction of an industrial order to the region's agricultural production (Figure 8). Whether change in the modus of agricultural production and following sales would affect the qualities and underpinning domestic orders of products "made in Noto" is in question. The order of industry becomes dominant in the productions and sales of the vegetables from Noto GIAHS. It was the underpinning driver behind the increase in quantity of the vegetables in Noto and Jiwa-mall. Labeling factory-made lettuce with 
Noto leads to a question on the stable identification of locality as well as sustainability and traditionality which stakeholders involved with the GIAHS emphasize and value.
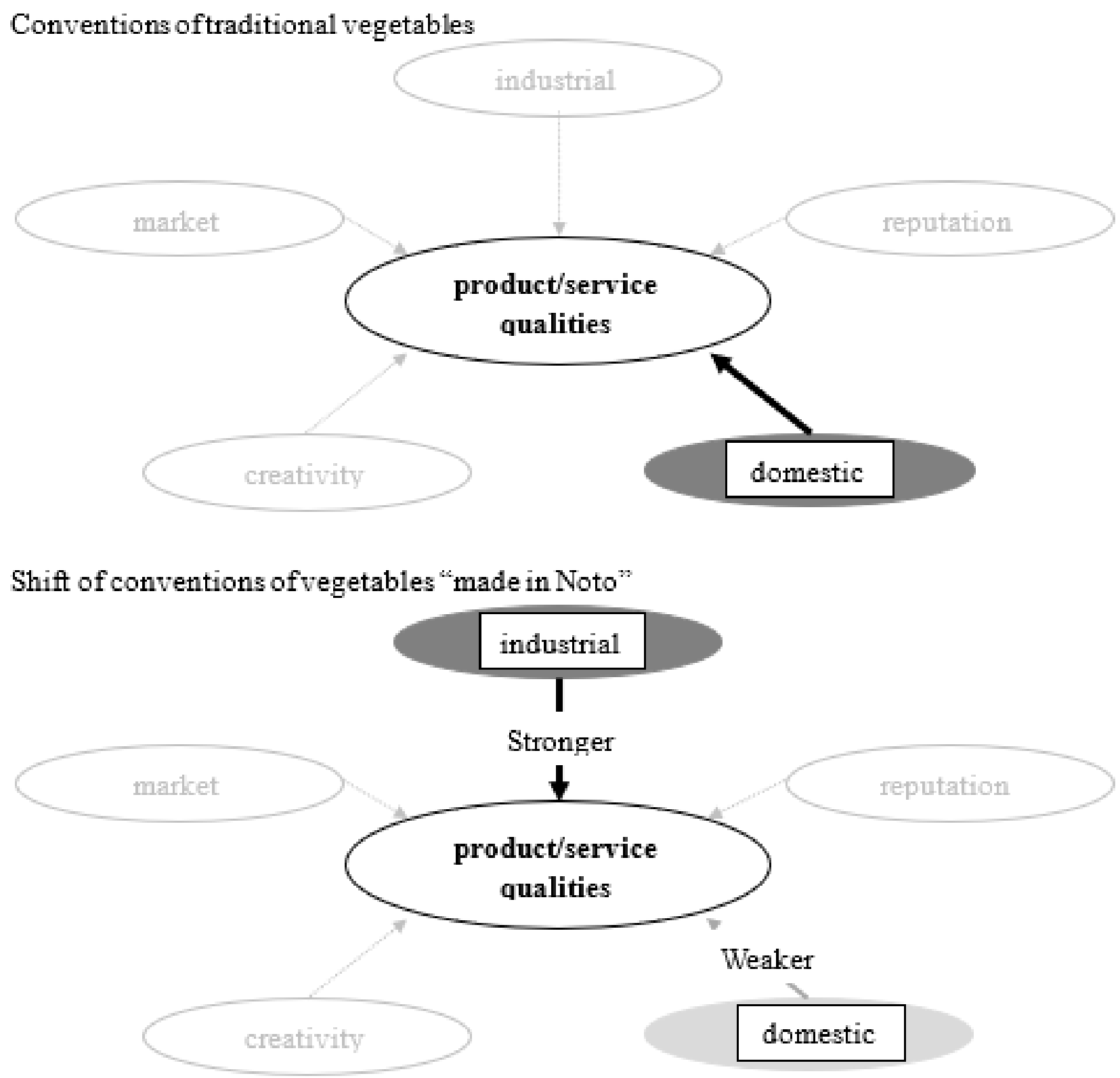

Figure 8. Shift of conventions of Noto vegetables and ones labeled with Noto as the place name.

\subsection{Limitations of the Study}

This study focused on the sales data of four vegetable types, including categories of traditional vegetables to highlight the shifting meanings of traditionality and locality in the heritage system in temporal scales. The limitations of the study included the inclusion of the survey on producers, retail locations of study, consumer preference, and the policy promotion. First, the study did not involve the survey on producers of the four kinds of vegetables, especially Noto vegetables. This will identify the factors of trade decrease in a more comprehensive way while this study depended on the sales data and the interviews with traders and retailers. Second, the study focused on the sales in Jiwa-mall as the retail measure. While the study focused on the situation of the sales of traditional vegetables to consumers positive about traditional and local vegetables in the prefecture, the data on the sales within local areas producing the vegetables may enrich the understanding 
on the distribution and sales of the vegetables in the study. Third, this study did not ask consumers about their preference on the vegetable categories. Thus, the study could not directly estimate the impact of this preference on the sales trends of the vegetables in each category. Lastly, the study did not explore the roles of policy targeting the production and consumption of Noto and Kaga vegetables. To secure a place to sell in cities, Noto vegetables need the production to increase and a more affirmative policy environment.

\section{Conclusions}

Comparing the sales of the four categories of vegetables, traditional vegetables in a GIAHS site symbolically disappeared in 2018 from the items listed in the local food catalog of Jiwa-mall. At a conceptual level, compared with Noto vegetables, Kaga vegetables are relatively grounded in local nature and society. This could facilitate better communication with consumers. Kaga vegetables are stricter with the registrations to limit the vegetables with a production history dating back to at least 1945 [8]. On the other hand, Noto vegetables are varieties with about 30 years of production history or longer, or varieties that were selected for production promotion. The solidification of quality can differentiate Kaga vegetables in sales [20].

Adding place names to the vegetables could increase sales [8]. A place name of the agricultural region could represent the region's agricultural tradition and legacy. The products that respect these local or domestic productions are related to a domestic order of worth in Convention Theory [21-23]. The results of this study indicate that both traditional and non-traditional local foods seemingly increased their volumes framed under domestic "local order" tagged with local names. Yet that increase was eclipsed, and further increases were actualized largely by products in the "industrial order" symbolized by lettuce produced in plant factories. For many historical agricultural regions in Japan, including the Noto and Kanazawa regions, place names can be one of the bases for agricultural marketing, agritourism, and location marketing. However, the vegetables with place names in this study did not indicate a straight path to agricultural revitalization. Furthermore, plant factories in the Noto region take advantage of the place name to sell their lettuce. Their use of the word "Noto" creates uncertainty or confusion about Noto's place name. This is because the current success of the plant factories is much less likely to be attributable to Noto's GIAHS, its farming culture, and its ecosystem despite a certain added flavor of domestic order. The future effects of that current success are to be studied especially on the consumer awareness and marketing strategies for Noto's agriculture and regional tourism and future development.

To align with the intentions of the GIAHS registration program, agricultural communities and governments connected with registered sites are supposed to raise their capacities to preserve their agricultural landscapes. Agricultural production in a site is expected to play a role in the conservation of the landscape and the revitalization of local agriculture and communities. Evidence to monitor agricultural production in the GIAHS site needs to include more data on the trends of promotion and sales besides those at the production stage. This study showed that as a group, farmers from the Noto GIAHS site have become too old to sustain production of the traditional vegetables. This demands the revision of the plan to conserve the agricultural landscape by means of vegetable production. The revised plan would survey the strategies of traditional vegetable production in other regions, including Kanazawa City. Farmers and the related governments and organizations might also explore the ways that continuous and well-designed public campaigns could increase interest in agricultural production unique to the region. Once the landscape and its unique products, including traditional vegetables, attract the attention of distributors, retailers, and consumers in a sustainable way, the production of traditional vegetables can probably involve both farmers and agricultural corporations. The production volume can be enough to sell in regional supermarkets and co-ops, and it can maintain the landscape. This can also involve the governmental support of the extension centers of the prefectural governments, and agricultural cooperatives [28]. 
GIAHS sites are underpinned by unique and fascinating landscapes. Farmers and related governments and organizations need to plan, and to implement plans, for landscape conservation. Scholars and practitioners need to further exchange and share information about the ongoing situation of GIAHS sites. The comparison with traditional and non-traditional vegetable categories in both a GIAHS area and the surrounding region in this study can contribute to the planning and evaluation for the conservation of the GIAHS through agricultural production. This can contribute to evidence-based policy making (EBPM) to understand the prospect of rural development through the promotion of traditional vegetables and the conservation of the GIAHS areas with similar themes and objectives. Jámbor et al. [29] and Wang et al. [30] tried to analyze the information to strategize a plan for agricultural development. EBPM can also effectively monitor the implementation of the strategies and plans. EBPM needs to be encouraged in both planning and monitoring for sustainable conservation of GIAHS areas. From the analysis of sales data, this study demonstrated that the Noto region has difficulty in sustaining the production of the traditional vegetables by the aging farming community. They can surely learn from the sales efforts for Kaga vegetables. Simultaneously, it would be useful to seek practices to accomplish the production and sale of agricultural products, as well as landscape conservation, in the GIAHS site. The linkage among capacity building, sustainable productions and sales of products with intended qualities, and landscape conservation will be an issue for rural communities with agricultural productions specific to their landscapes. SBPM with diverse data will promote, conserve, and develop communities involved with the GIAHS.

Author Contributions: Conceptualization, Y.U., Y.F. and R.K.; data curation, Y.U. and Y.F.; formal analysis, Y.M. and Y.F.; funding acquisition, R.K.; investigation, R.K.; methodology, Y.M., Y.U., Y.F. and R.K.; resources, R.K.; supervision, R.K.; validation, Y.F.; visualization, Y.U. and Y.F.; writingoriginal draft, Y.M. and R.K.; writing—review and editing, Y.U., Y.F. and R.K. All authors have read and agreed to the published version of the manuscript.

Funding: The work was supported by Kunisaki Peninsula Usa Area GIAHS Research Project; Han Chang-Woo-Tetsu Cultural Foundation; Policy Research Institute, MAFF of Japan as the Commissioned Project on the Policy Science of Agriculture, Forestry, and Fisheries from the year 2018 to 2020: Factors to Facilitate Production and Export of Organic Agricultural Products: Analysis of Status and Trends in EU and Implications for Japan; JSPS KAKENHI Grants (JP16KK0053 and JP17K02105); JST RISTEX (Grant Number JPMJRX20B3), Japan; and the Kurita Water and Environment Foundation [20C002].

Conflicts of Interest: The authors declare no conflict of interest.

\section{References}

1. Food and Agriculture Organization of the United Nations (FAO). Chronology of Development of the GIAHS Programme. Available online: http:/ / www.fao.org/giahs/background/a-global-partnership/en/ (accessed on 10 May 2021).

2. Yiu, E.; Nagata, A. The Road to Globally Important Agricultural Heritage Systems (GIAHS): United Nations University's Journey with Local Communities; United Nations University Institute for the Advanced Study of Sustainability Unit: Tokyo, Japan, 2018.

3. Koohafkan, P.; Altieri, M.A. Globally Important Agricultural Heritage Systems: A Legacy for the Future; Food and Agriculture Organization of the United Nations: Rome, Italy, 2011.

4. Food and Agriculture Organization of the United Nations (FAO). Become a GIAHS. Available online: http://www.fao.org/ giahs/become-a-giahs/designation-process/en/ (accessed on 10 May 2021).

5. Food and Agriculture Organization of the United Nations (FAO). Goal and Objectives. Available online: http://www.fao.org/ giahs/background/goal-and-objectives/en/ (accessed on 10 May 2021).

6. Bixia, C.; Zhenmian, Q. Green tourism in Japan: Opportunities for a GIAHS pilot site. J. Resour. Ecol. 2013, 4, 285-292. [CrossRef]

7. Ishikawa Prefecture. Ishikawa Statistical Information. Available online: http://toukei.pref.ishikawa.jp/index.asp (accessed on 10 May 2021).

8. Uchiyama, Y.; Fujihira, Y.; Matsuoka, H.; Kohsaka, R. Tradition and Japanese vegetables: History, locality, geography, and discursive ambiguity. J. Ethn. Foods 2017, 4, 198-203. [CrossRef]

9. Igarashi, K.; Abe, S.; Satoh, J. Effects of atsumi-kabu (red turnip, Brassica campestris L.) anthocyanin on serum cholesterol levels in cholesterol-fed rats. Agric. Biol. Chem. 1990, 54, 171-175. [CrossRef] 
10. Igarashi, K.; Mikami, T.; Takahashi, Y. Comparison of the preventive activity of isorhamnetin glycosides from atsumi-kabu (red turnip, Brassica, campestris L.) leaves on carbon tetrachloride-induced liver Injury in mice. Biosci. Biotechnol. Biochem. 2008, 72, 856-860. [CrossRef] [PubMed]

11. Igarashi, K.; Yoshida, T.; Suzuki, E. Antioxidative activity of nasunin in choujanasu (little eggplant, Solanum melongena L.'chouja'). Nippon Shokuhin Kogyo Gakkaishi 1993, 40, 138-143. [CrossRef]

12. Egashira, H. Yasai no zairai hinshu o tazunete-Sono tabe-kata kara kangaeta koto [What I think through seeing and eating local vegetable varieties on the traditional cultivated area]. Jpn. Soc. Cook. Sci. 2015, 48, 432-434.

13. Egashira, H.; Nitta, A.; Morita, A. Dadachamame no shurui to rekishi [Varieties and history of dadachamame]. Technol. Cult. Agric. 2003, 26, 87-100.

14. Rath, E.C. New meanings for old vegetables in Kyoto. Food Cult. Soc. 2014, 17, 203-223. [CrossRef]

15. de St. Maurice, G. Everything but the taste: Kyoto's shishigatani squash as culinary heritage. Food Cult. Soc. 2017, 20, 281-301. [CrossRef]

16. Kohsaka, R.; Tomiyoshi, M. Dentō Yasai no Ima Chiiki no Torikumi, Chiri-Teki Hyōji no Hogo to Iden Shigen [Traditional Vegetables in the Contemporary Era: Local Attempts and Protections of Geographical Indications and Genetic Resources] in Asahi-eco Books; Shimizukobundo: Tokyo, Japan, 2015.

17. Office for Promotion Council of Noto Vegetables. Noto Yasai To Wa [What are Noto Vegetables]? Department of Agricultural Promotion, General Office of Agriculture and Forestry in Nakanoto, Ishikawa Prefecture. Available online: http://noto-yasai.jp/ about/index.html (accessed on 10 May 2021).

18. Kohsaka, R.; Tomiyoshi, M.; Matuoka, H. Tourist perceptions of traditional Japanese vegetable brands: A quantitative approach to Kaga vegetable brands and an information channel for tourists at the Noto GIAHS site. In Aquatic Biodiversity Conservation and Ecosystem Services; Nakano, S., Yahara, T., Nakashizuka, T., Eds.; Springer: Berlin/Heidelberg, Germany, 2016; pp. 109-121.

19. Allaire, G.; Daviron, B. (Eds.) Ecology, Capitalism and the New Agricultural Economy: The Second Great Transformation; Routledge: London, UK, 2019.

20. Boyer, R.; La Allaire, G. Grande Transformation de l'Agriculture [The Great Transformation of Agriculture]; French National Institute for Agricultural Research (INRA): Paris, France, 1995.

21. Boltanski, L.; Thévenot, L. On Justification: Economies of Worth; Princeton University Press: Princeton, NJ, USA, 2006.

22. Wilkinson, J. Convention theory. In Encyclopedia of Consumer Culture; Southerton, D.D., Ed.; SAGE Publications: Thousand Oaks, CA, USA, 2011; Volume 1, pp. 359-362.

23. Ponte, S. Convention theory in the Anglophone agro-food literature: Past, present and future. J. Rural Stud. 2016, 44, 12-23. [CrossRef]

24. Consumer Co-operative Institute of Japan. (Ed.) Toward Contemporary Co-Operative Studies: Perspectives from Japan's Consumer Co-Ops; The Consumer Co-operative Institute of Japan: Tokyo, Japan, 2009.

25. Kanazawa City Agricultural Produce Branding Association. Kaga Vegetables. Available online: http://www.kanazawakagayasai.com/global/en/ (accessed on 10 May 2021).

26. Nihon Keizai Shimbun. Ishikawa Nakanotomachi ni Retasu Kōjō Ken'nai 2 Kashome ga Kadō: Shokubutsu kōjō no Baitekku Bejitaburufakutorī [Lettuce Factory in Naka-Noto Town, Ishikawa. The Second Production Center is Operating in the Prefecture: The Vegetable Factory by Vitec Vegetable Factory]. 2018. Available online: https:/ / www.nikkei.com/article/DGXMZO3372637 0S8A800C1LB0000/ (accessed on 10 May 2021).

27. Storper, M.; Salais, R. Worlds of Production: The Action Frameworks of the Economy; Harvard University Press: Cambridge, MA, USA, 1997.

28. Kishioka, T.; Hashimoto, S.; Nishi, M.; Saito, O.; Kohsaka, R. Fostering cooperation between farmers and public and private actors to expand environmentally friendly rice cultivation: Intermediary functions and farmers' perspectives. Int. J. Agric. Sustain. 2017, 15, 593-612. [CrossRef]

29. Jámbor, A.; Czine, P.; Balogh, P. The impact of the coronavirus on agriculture: First evidence based on global newspapers. Sustainability 2020, 12, 4535. [CrossRef]

30. Wang, N.; Zhu, L.; Bing, Y.; Chen, L.; Fei, S. Assessment of urban agriculture for evidence-based food planning: A case study in Chengdu, China. Sustainability 2021, 13, 3234. [CrossRef] 